\title{
Effectiveness of transversus abdominis plane block for laparoscopic appendectomy in non-perforated acute appendicitis
}

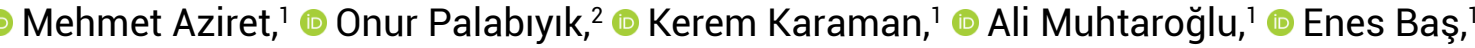 \\ Volkan Öter, ${ }^{1}$ ๑ Metin Ercan, ${ }^{1}$ ๑ Fehmi Çelebi, ${ }^{1}$ ๑ Erdal Birol Bostancı ${ }^{3}$ \\ 'Department of General Surgery, Sakarya University Training and Research Hospital, Sakarya, Turkey \\ 2Department of Anesthesiology, Sakarya University Training and Research Hospital, Sakarya, Turkey \\ ${ }^{3}$ Department of Gastroenterology Surgery, Health Sciences University, Ankara Yüksek Ihtisas Hospital, Ankara, Turkey
}

\begin{abstract}
Introduction: One of the most important goals in abdominal surgery is to reduce as much as possible the postoperative pain and increasing patients comfort. We aimed to assess the analgesic efficacy of the transversus abdominis plane block (TAP) in patients with non-perforated acute appendicitis undergoing laparoscopic appendectomy (LA).
\end{abstract}

Materials and Methods: Seventy patients who underwent LA were divided retrospectively into two groups; the LA group (control group: $n=39$ ) and the LA group with TAP-block (treatment group; $n=31$ ). The present study was planned retrospectively but the data was collected prospectively. Groups were compared regarding age, gender, perioperative symptoms and signs, such as physical operation time, postoperative pain score (visual analogue scale $=$ VAS), hospitalization period stay time, postoperative complications, and return to normal daily activity.

Results: The mean VAS score in LA+TAP-block group was $3.1 \pm 2.1 ; 3.3 \pm 2.1 ; 3.9 \pm 2.3 ; 4.2 \pm 2.6$ and $4.3 \pm 3$ on the $0^{\text {th }} ; 2^{\text {th }} ; 6^{\text {th }} ; 16^{\text {th }}$ and $24^{\text {th }}$ hours and $4 \pm 1.5 ; 4.7 \pm 2.2 ; 6 \pm 2 ; 6.2 \pm 2$ and $5.9 \pm 2$ on the $0^{\text {th }} ; 2^{\text {th }} ; 6^{\text {th }} ; 16^{\text {th }}$ and $24^{\text {th }}$ hours in only LA group, respectively. Postoperative abdominal pain was significantly less in LA+TAP-block group than the LA group at $2^{\text {th }}(p=0.01), 6^{\text {th }}(p<0.01), 16^{\text {th }}(p<0.001)$ and $24^{\text {th }}(p=0.01)$ hours. Although, statistically not significant, TAP-block was associated with more quickly to return to normal daily activities.

Conclusion: USG-guided TAP block can improve significantly postoperative abdominal pain during the first 24 hours in laparoscopic appendectomy performed patients.

Keywords: Appendectomy; laparoscopic; postoperative abdominal pain; transversus abdominis plane (TAP) block.

\section{Introduction}

Acute appendicitis (AP) is the most common abdominal surgery performed worldwide. ${ }^{[1]}$ Early diagnosis is crucial because AP can be complicated to; perforation, plastron appendicitis subsequent abscess formation and thrombophlebitis. $^{[2,3]}$ Laparoscopic appendectomy (LA), take 
much more place day by day. ${ }^{[4]}$ Patient with LA is associated with lower postoperative abdominal pain, early mobilization and more quickly return to the normal daily activity. ${ }^{[5]}$

Postoperative abdominal pain affects negatively the daily-life and is an important complaint and problem following abdominal surgery. ${ }^{[6,7]}$ Transversus abdominis plane block (TAP-block) is a minimal invasive analgesic method which is effective in decreasing postoperative abdominal pain. ${ }^{[7]}$ TAP-block has enjoyed a surge in popularity for two decades although there are some debates associated with failed to add any analgesic benefit in some trials. ${ }^{[7-10]}$

In the present study, we aimed to compare patients with AP who underwent preoperative TAP block with those who did not in terms of age, gender, perioperative symptoms and signs, operation time, postoperative pain, hospitalization period, postoperative complications, and return to normal daily activity.

\section{Materials and Methods}

\section{Methodology and Ethics}

After approval of the ethical committee, 70 consequence patients who underwent LA in our clinic between January 2018 and July 2018 were retrospectively analyzed. Patients were divided into two groups: patients who underwent TAP-block prior LA (treatment group; $\mathrm{n}=31$ ) and patients who did not (control group; $n=39$ ) The two groups were compared regarding age, gender, perioperative symptoms and signs, operation time, postoperative pain score (visual analogue scale = VAS), hospitalization period, postoperative complications, and return to normal daily activity. The diagnosis of acute appendicitis was made according to physical examination and laboratory and imaging findings. Informed consent was taken from all patients, and approval for the study protocol was obtained from the Ethical Committee of our center.

\section{Inclusion Criteria}

Patients -between the ages 18 and 65 years- who were willing to give written informed consent were included to the study with an international normalizing ratio (INR) $<1.5$, a prothrombin time (PT) $<15$ seconds, partial thromboplastin (APTT) within normal ranges, and platelet counts $>50,000 / \mathrm{mm}^{3}$.

\section{Exclusion Criteria}

Patients who were not willing to give informed consent and patients with; perforated appendicitis, ovarian cyst rupture and tuba-ovarian abscess, chronic obstructive pulmonary disease, congestive heart failure, multi organ failure, systemic connective tissue diseases or rheumatism and a history of the TAP-block hypersensitivity were excluded from the study.

First-generation cephalosporin was given for antibiotic prophylaxis in all patients. The operation time was defined as the time beginning with the induction of anesthesia until to extubation. Following the operation, an intramuscular injection of $75 \mathrm{mg}$ of diclofenac sodium was administered to all patients, if patients' VAS score was $>4$ points. Every patient received liquid foods after $6-8$ hours from the operation.

\section{General Anesthesia and TAP-Block Procedure}

After preoperative anesthetic evaluation and 8 hours starvation the patients were taken to the operation room. Patients were monitored to assess heart rate (HR), noninvasive mean arterial pressure (MAP) and peripheral oxygen saturation $\left(\mathrm{SpO}_{2}\right)$, a crystalloid solution at $10 \mathrm{~mL} / \mathrm{kg} /$ hour was begun intravenously. A standardized general anesthesia protocol was administered for all patients; induction of anesthesia was performed using $2-3 \mathrm{mg} / \mathrm{kg}$ of propofol, $1-2 \mu \mathrm{g} / \mathrm{kg}$ of fentanyl, $0.6 \mathrm{mg} / \mathrm{kg}$ of rocuronium, and mechanical ventilation was maintened with desflurane in an oxygen-enriched air mixture. An ultrasound (US)-guided TAP-block, described by Hebbard et al., ${ }^{[9]}$ was performed bilaterally in all patients within supine position using an aseptic technique. The patients received $20-\mathrm{mL}$ of injections including $1 \%$ of lidocaine and $0.25 \%$ of bupivacaine to each side of the abdominal wall. An US probe was directed in the mid-axillary line at the midpoint between the inferior costal margin and iliac crest. The skin, subcutaneous fat tissue, external oblique muscle, internal oblique muscle, transversus abdominis muscle, and peritoneum were clearly visualized with the US probe by moving from cephalic to caudal direction. The peripheral nerve block needle was controlled in the same plane as the US probe (in-plane technique) and inserted between the internal oblique and transversus abdominis muscles. A mixed local anesthetic of $20 \mathrm{ml}$ was given meticulously after entering the neurofascial area (Fig. 1a and b). 

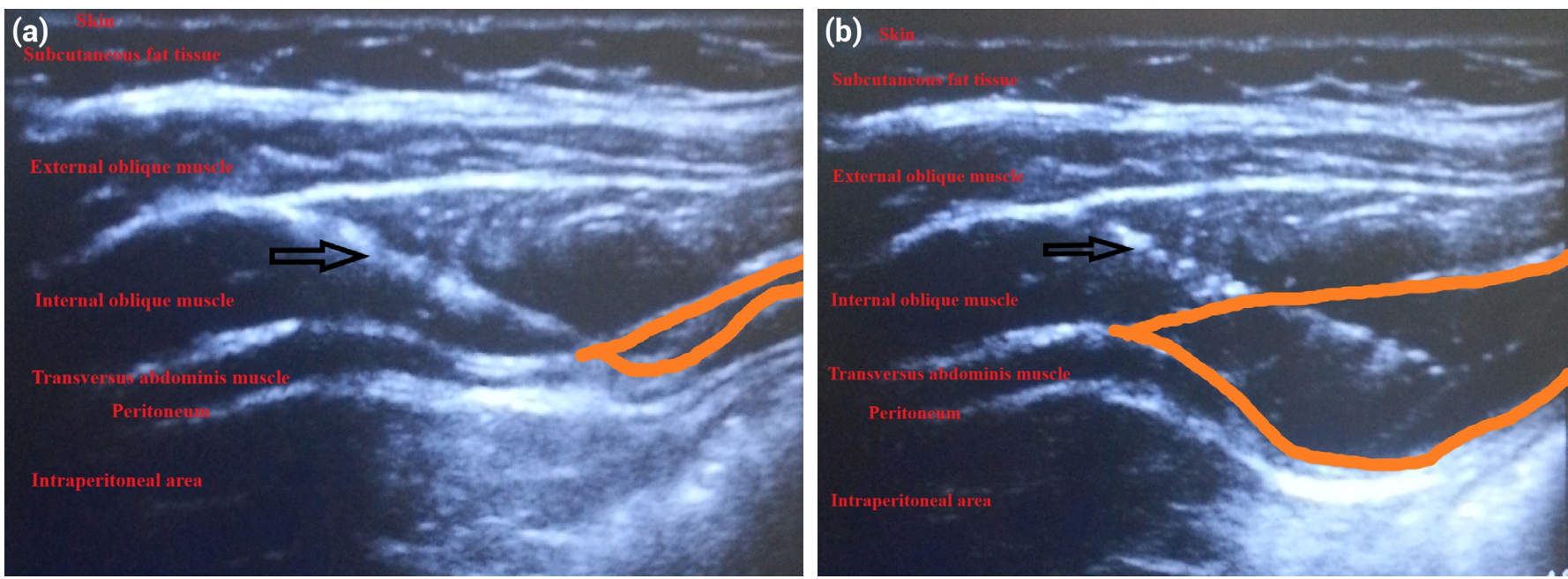

Figure 1. $(\mathbf{a}, \mathbf{b})$ USG-guided TAP block procedure (Arrow: The peripheral nerve block needle; the area between the orange colored lines: the distribution of local anesthetic solution in the neurofascial area).

\section{Laparoscopic Appendectomy}

The North American three-port technique was used on all patients under general anesthesia. Pneumo-peritoneum was provided with carbon dioxide $\left(\mathrm{CO}_{2}\right)$ and intraabdominal pressure was fixed at $10-12 \mathrm{mmHg}$ after inserted under the umbilicus using the Veress needle. A $10 \mathrm{~mm}$ trocar was inserted, and then a $5 \mathrm{~mm}$ trocar was inserted into the suprapubic area before placing a $10 \mathrm{~mm}$ trocar to the left iliac fossa under direct vision. The possibility of hemorrhage or organ injury occurring in connection with trocar was controlled prior to performing the appendectomy. After the appendix was visible, it was lifted from the mesoappendix. A $10 \mathrm{~mm}$ bipolar vessel sealer (Liga- SureTM Valley lab, Tyco, USA) was used for the mesoappendix dissection. Once the base of the appendix was revealed, it was ligated with 2/0 silk (10-12 cm) using the intracorporeal knotting technique or endo-loops. Appendectomy specimen was then removed trough the $10 \mathrm{~mm}$ trocar using endo-bag. In the case with a suppurated appendicitis, the appendectomy area was irrigated with serum physiologic $(0.9 \%$ sodium-chloride) and then aspirated and a drain was inserted. The patients were hospitalized overnight. After discharge, all patients were controlled by same authors at the clinic on the third and $7^{\text {th }}$ days.

\section{Assessment of Pain (Visual Analogue Scale $=$ VAS)}

The degree of postoperative pain was evaluated using the VAS score at $0^{\text {th }}, 2^{\text {th }}, 8^{\text {th }}, 16^{\text {th }}$ and $24^{\text {th }}$ hours. Pain scores were numbered from 1 to 10 , with 1 indicating no pain and 10 indicating the highest level of pain, requiring significant analgesic intervention. Pain assessment was administered carefully by two general surgery assistants under the supervision of a general surgeon to all patients. Following surgery, pain assessments were measured by the patients' bed at the end of $0^{\text {th }}, 2^{\text {th }}, 8^{\text {th }}, 16^{\text {th }}$ and $24^{\text {th }}$ hours.

\section{Statistical Analysis}

The statistical analyzes were performed using SPSS (Statistical Package for the Social Sciences ver. 21.0, SPSS Inc, Chicago, Illinois, USA) computer program. Indepented-Samples T test was used for comparison of age, BMI, length of hospital stay, follow up and operation time between the groups. Complications were analyzed with the $\chi^{2}$ test. Chisquare and Fisher's exact chi-square tests were used for comparison of categorical variables. Mann Whitney U-test was used when the groups were not distributed normally. For all statistical analyzes $\mathrm{p}<0.05$ was accepted as significant.

\section{Results}

\section{Clinical, Operative Characteristics and Complications}

Out of a total of 79 patients, 70 were enrolled in the study, with 9 patients being excluded for failing to meet the inclusion criteria. The groups were divided into the following two groups: only LA group (control group; $n=39$ ), and LA group with prior TAP-block (treatment group; $n=31$ ). The mean age was $33.9 \pm 14.3$ years in LA group and $32 \pm 13.1$ years in LA+TAP-block group, $(\mathrm{p}=0.57)$. The LA group consisted of 18 females and 21 males, while LA+TAP-block group consisted of 12 females and 19 males. The body mass index (BMI) was $25.5 \pm 5.9 \mathrm{~kg} / \mathrm{m}^{2}$ in LA group and $24.1 \pm 6.6 \mathrm{~kg} / \mathrm{m}^{2}$ in LA+TAP-block group, $(\mathrm{p}=0.35)$ (Table 1, 2). Number of the comorbidities was $13(18.7 \%)$ in LA group and $9(12.8 \%)$ in group LA+TAP-block group, respectively (Table 1). 
Table 1. Clinical, operative characteristics and complications between groups

\begin{tabular}{|c|c|c|c|}
\hline & Control group $(n=39)$ & TAP block group $(n=31)$ & $\mathbf{p}$ \\
\hline Gender (Male/Female) & $21 / 18$ & $19 / 12$ & 0.53 \\
\hline Age & $33.9 \pm 14.3$ & $32 \pm 13.1$ & 0.57 \\
\hline Body mass index & $25.5 \pm 5.9$ & $24.1 \pm 6.6$ & 0.35 \\
\hline Comorbidity & 13 & 9 & 0.60 \\
\hline Hypertension & 1 & 1 & \\
\hline Dysmenorrhea & 1 & 0 & \\
\hline Diabetes mellitus & 2 & 0 & \\
\hline Obesity & 1 & 1 & \\
\hline Anxiety, migraine & 2 & 2 & \\
\hline Arthritis, lumbago, myalgia & 3 & 1 & \\
\hline Polycystic over syndrome & 1 & 0 & \\
\hline Dermatitis, allergic rhinitis & 1 & 1 & \\
\hline Benign prostate hyperplasia & 1 & 1 & \\
\hline Coroner artery disease & 0 & 1 & \\
\hline Bronchial asthma & 0 & 1 & \\
\hline Length of hospital stay (days) & $1.61 \pm 0.7$ & $1.51 \pm 0.5$ & 0.37 \\
\hline Follow up (months) & $4.1 \pm 1.5$ & $3.4 \pm 1.8$ & 0.09 \\
\hline Drain using & 3 & 5 & 0.452 \\
\hline Operation time & $77.2 \pm 22.6$ & $83.5 \pm 25.2$ & 0.63 \\
\hline Complications & 1 & 2 & 0.58 \\
\hline Hematoma & - & 1 & \\
\hline Surgical site infection & 1 & - & \\
\hline Intraabdominal collection & - & 1 & \\
\hline
\end{tabular}

TAP block: Transversus abdominis plane block.

Total follow-up time was 3180 days, with the mean follow-up time was $3.8 \pm 1.7$ months. The mean follow-up time was 4.1 \pm 1.5 months in LA group and $3.4 \pm 1.8$ months in LA+TAP-block group.

The mean lengths of hospital stay were $1.61 \pm 0.7$ days in LA group and $1.51 \pm 0.5$ days in LA+TAP-block group, respectively ( $p>0.05$ ). The mean operation time of TAP-block and LA group was higher than only LA group (83.5 \pm 25.2 versus 77.2 \pm 22.6$)(\mathrm{p}=0.63)$.

A drain was used in patients with suspected hemorrhage and pelvic abscess fluid (3 patients in the LA group (4.2\%) and group 2 patients in the LA+TAP-block group (7.1\%), $(\mathrm{p}=0.452)$ (Table 1$)$.

Mortality did not occur. Surgical site infection was observed in one patient in control group. In this patient, wound culture was taken, prophylactic antibiotics were started and surgical site care was administered until complete healing took place. A patient with subcutaneous hematoma was drained and surgical site care was performed daily. In patient with intraabdominal collection was consulted interventional radiologist. An abdominal collection was drained percutaneously after medical treatment. Among both groups, a major complication was not observed such as stump appendicitis, massive hemorrhage or appendectomy stump leakage (Table 1).

\section{Assessment of Pain}

The mean pain VAS score ${ }^{[10]}$ was found to be significantly lower in the LA+TAP-block group than the LA group. The mean VAS score in LA+TAP-block group was in order $3.1 \pm 2.1 ; 3.3 \pm 2.1 ; 3.9 \pm 2.3 ; 4.2 \pm 2.6$ and $4.3 \pm 3$ at $0^{\text {th }}, 2^{\text {th }}, 6^{\text {th }}$, $16^{\text {th }}$ and $24^{\text {th }}$ hours. The mean VAS score in LA group was $4 \pm 1.5 ; 4.7 \pm 2.2 ; 6 \pm 2 ; 6.2 \pm 2$ and $5.9 \pm 2$ at $0^{\text {th }}, 2^{\text {th }}, 6^{\text {th }}, 16^{\text {th }}$ and $24^{\text {th }}$ hours, respectively. When compared the VAS scores, pain was significantly lower in the LA+TAP block group than the LA group $\left(2^{\text {th }}\right.$ hour: $p=0.01 ; 6^{\text {th }}$ hour: $p<0.01 ; 16^{\text {th }}$ hour: $p<0.001$ and $24^{\text {th }}$ hour: $p=0.01$, respectively), (Table 
Table 2. Postoperative VAS scores and clinical outcomes in groups

\begin{tabular}{|c|c|c|c|c|c|}
\hline & \multirow[t]{2}{*}{$\begin{array}{l}\text { Control group } \\
\qquad(n=39)\end{array}$} & \multirow[t]{2}{*}{$\begin{array}{l}\text { TAP block group } \\
\qquad(n=31)\end{array}$} & \multicolumn{2}{|c|}{$\begin{array}{l}95 \% \text { Confidence interval } \\
\text { of the difference }\end{array}$} & \multirow[t]{2}{*}{$\mathbf{p}$} \\
\hline & & & Lower & Upper & \\
\hline \multicolumn{6}{|l|}{ Pain VAS scores } \\
\hline $0^{\text {th }}$ & $4 \pm 1.5$ & $3.1 \pm 2.1$ & 0.07 & 1.68 & 0.07 \\
\hline $2^{\text {th }}$ & $4.7 \pm 2.2$ & $3.3 \pm 2.1$ & 0.27 & 2.38 & 0.01 \\
\hline $6^{\text {th }}$ & $6 \pm 2$ & $3.9 \pm 2.3$ & 1.03 & 3.14 & $<0.001$ \\
\hline $16^{\text {th }}$ & $6.2 \pm 2$ & $4.2 \pm 2.6$ & 0.84 & 3.16 & 0.001 \\
\hline $24^{\text {th }}$ & $5.9 \pm 2$ & $4.3 \pm 3$ & 0.34 & 2.89 & 0.01 \\
\hline Return to normal activity (days) & $2.5 \pm 0.8$ & $2.2 \pm 1.1$ & -0.19 & 0.77 & 0.24 \\
\hline Time to working (days) & $7.8 \pm 2.7$ & $7.0 \pm 2.2$ & -0.55 & 2.19 & 0.21 \\
\hline
\end{tabular}

2). Return to normal activity was $2.5 \pm 0.8$ days in LA group and 2.2 \pm 1.1 days in LA+TAP block group, ( $>0.05)$. Return to working time was $7.8 \pm 2.7$ days in LA group and 7.0 \pm 2.2 days in the LA+TAP -block group, (p>0.05) (Fig. 2 and 3) (Table 2).

\section{Discussion}

Acute appendicitis is the most common abdominal emergency world-wide. ${ }^{[1-3]}$ LA has replaced with OA within increasing frequency since three decades. ${ }^{[4,5]}$

Postoperative abdominal pain is an important problem following surgery and it is directly related with quality

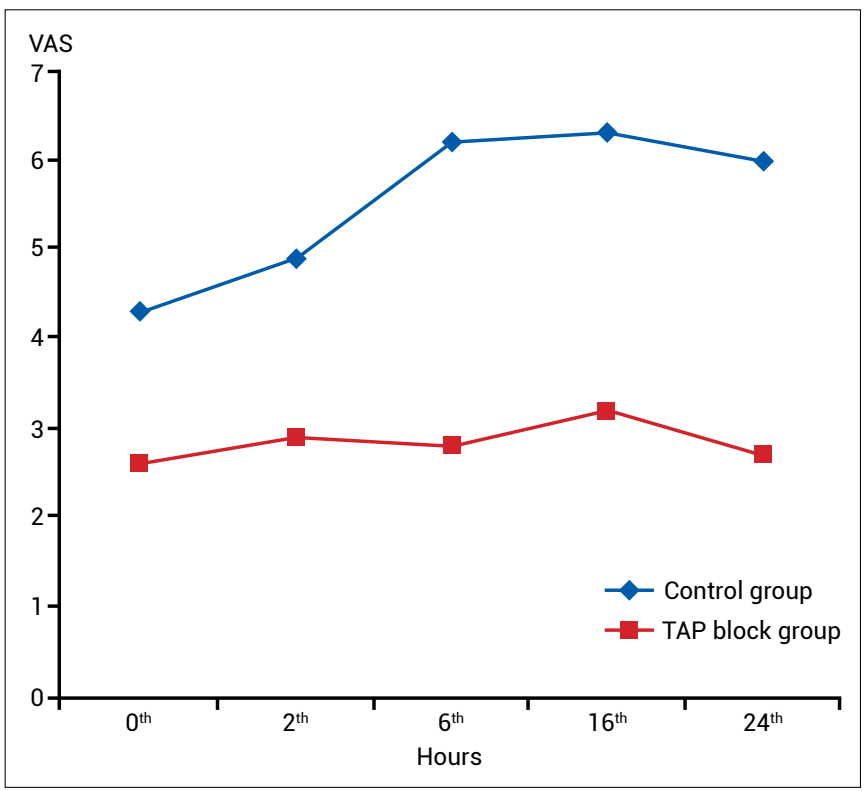

Figure 2. Pain scores at postoperative time for the control and TAP block groups (VAS: Visual analog scale). and conformity of life. Minimal invasive procedures had been increased to use due to decreased postoperative abdominal pain, less intraoperative bleeding, less hospital stay and less hospital cost. ${ }^{[4-6]}$ Furthermore, it can reduce patients' tolerance and compliance to the treatment. ${ }^{[6]}$ There are several methods for abdominal pain relief including pharmacological and minimal invasive procedures. ${ }^{[6,7]}$ In 2001, Rafi et al., ${ }^{[8]}$ first described the TAP- block which can be applied to different anatomical areas such as the iliohypogastric and ilioinguinal nerves and intercostal nerves. Recently, Hebbard et al. ${ }^{[9]}$ reported that TAP block is safe and effective when it is guided by US. Recently, US- guided TAP block has gained access

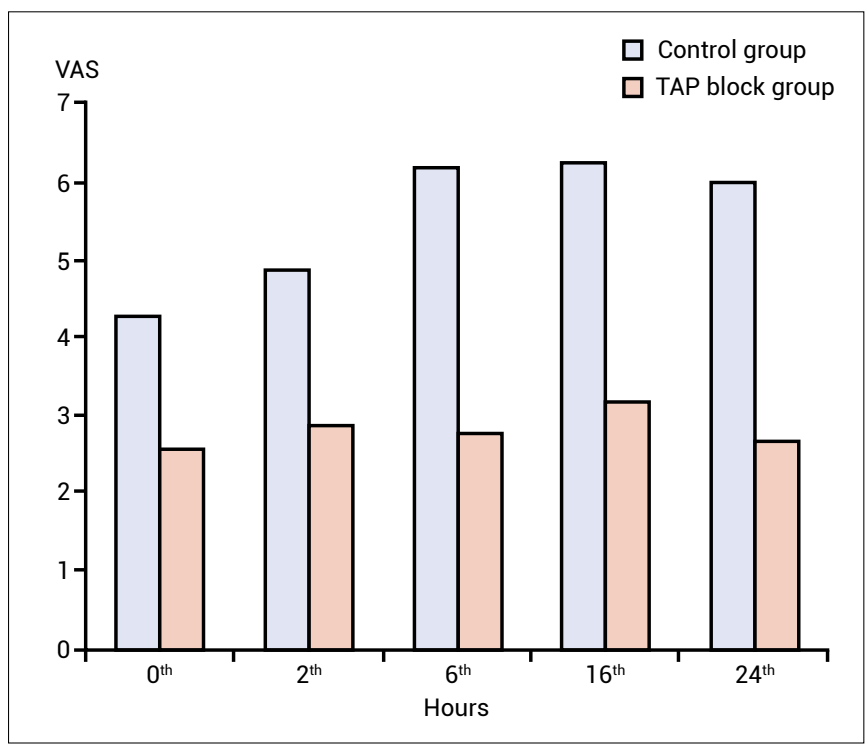

Figure 3. Pain scores at postoperative time for the control and TAP block groups during the 24-hour study (VAS: Visual Analog scale). 
worldwide. ${ }^{[7-9]}$ Many studies have reported that patients who have undergone abdominal surgery with TAP-block had less postoperative pain and with less need for analgesic use. ${ }^{[8-10]}$ Nevertheless, there are a limited number of studies in the literature which reveal postoperative pain association with TAP-block after laparoscopic appendectomy in adults. A prospective randomized trial by McDonnell et al. ${ }^{[1]}$ reported that TAP block supplied highly effective postoperative analgesia in the first 24 postoperative hours after major abdominal surgery. In a randomized controlled double-blinded clinical trial Niraj et al. ${ }^{[12]}$ showed that US-guided TAP block decreases substantially dose of the analgesic drugs and postoperative analgesia. Similarly, a randomized controlled study by Shaaban et al. ${ }^{[13]}$ detected that US-guided TAP block with $(0.4 \mathrm{ml} / \mathrm{kg})$ $0.25 \%$ bupivacaine provides extended postoperative analgesia with reduced analgesic use after appendectomy in children. On the other hand, a prospective randomizedcontrolled study by Tupper-Carey et al. ${ }^{[14]}$ which compare standard care with TAP-block for laparoscopic appendectomy found that TAP-block performed immediately prior to skin incision did not significantly make better postoperative analgesia outcomes and morphine consumption.

The present study investigated the effectiveness of the TAP-block following laparoscopic appendectomy. Our study groups (control and TAP-block) had similarly clinic features in terms of age, gender, BMI, co-morbidity, length of hospital stay (days), follow up, drain using, operation time and complications $(p>0.05)$. The similarity of these parameters is important in terms of revealing the pain scale of the groups in a real sense. This study showed LA+TAP-block group had significantly lower VAS scores than control group in first 24 hours following laparoscopic appendectomy. Further, patients in LA+TAP-block group return more quickly to working. In adults, there is only a prospective randomized study on TAP-block following laparoscopic appendectomy. In their study, Tupper-Carey et al. ${ }^{[14]}$ reported that TAP blockade did not significantly improve postoperative analgesia outcomes in 2017 but they performed the study from December 2012 to December 2013. Our study is retrospective but the data were collected prospectively with enough sample size and current information.

There were some limitations in the present study. First, it is retrospective. Secondly, TAP -block was not performed by the same anesthetists.

\section{Conclusion}

TAP-block prior to LA is associated with less postoperative pain, more quickly return to daily activity, and less need for analgesia.

\section{Acknowledgments}

The study is planned to present as an oral presentation at the $6^{\text {th }}$ national congress of gastroenterogical surgery

\section{Disclosures}

Ethichs Committee Approval: The study was approved by the Local Ethics Committee.

Peer-review: Externally peer-reviewed.

Conflict of Interest: None declared.

\section{References}

1. Addiss DG, Shaffer N, Fowler BS, Tauxe RV. The epidemiology of appendicitis and appendectomy in the United States. Am J Epidemiol 1990;132:910-25. [CrossRef]

2. Erdem H, Çetinkünar S, Daş K, Reyhan E, Değer C, Aziret M, et al. Alvarado, Eskelinen, Ohhmann and Raja Isteri Pengiran Anak Saleha Appendicitis scores for diagnosis of acute appendicitis. World J Gastroenterol 2013;19:9057-62. [CrossRef]

3. McBurney C. IV. The Incision Made in the Abdominal Wall in Cases of Appendicitis, with a Description of a New Method of Operating. Ann Surg 1894;20:38-43. [CrossRef]

4. Semm K. Endoscopic appendectomy. Endoscopy 1983;15:59-64. [CrossRef]

5. Aziret $\mathrm{M}$, Çetinkünar S, Erdem $\mathrm{H}$, Kahramanca Ş, Bozkurt $\mathrm{H}$, Dülgeroğlu $\mathrm{O}$, et al. Comparison of open appendectomy and laparoscopic appendectomy with laparoscopic intracorporeal knotting and glove endobag techniques: A prospective observational study. Turk J Surg 2017;33:258-66. [CrossRef]

6. Chou R, Gordon DB, de Leon-Casasola OA, Rosenberg JM, Bickler S, Brennan T, et al. Management of Postoperative Pain: A Clinical Practice Guideline From the American Pain Society, the American Society of Regional Anesthesia and Pain Medicine, and the American Society of Anesthesiologists' Committee on Regional Anesthesia, Executive Committee, and Administrative Council. J Pain 2016;17:131-57.

7. Abdallah FW, Chan VW, Brull R. Transversus abdominis plane block: a systematic review. Reg Anesth Pain Med 2012;37:193-209. [CrossRef]

8. Rafi AN. Abdominal field block: a new approach via the lumbar triangle. Anaesthesia 2001;56:1024-6. [CrossRef]

9. Hebbard P, Fujiwara Y, Shibata Y, Royse C. Ultrasound-guided transversus abdominis plane (TAP) block. Anaesth Intensive Care 2007;35:616-7.

10. Scott J, Huskisson EC. Graphic representation of pain. Pain 1976;2:175-84. [CrossRef] 
11. McDonnell JG, O'Donnell B, Curley G, Heffernan A, Power C, Laffey JG. The analgesic efficacy of transversus abdominis plane block after abdominal surgery: a prospective randomized controlled trial. Anesth Analg 2007;104:193-7. [CrossRef]

12. Niraj G, Searle A, Mathews M, Heffernan A, Power C, Laffey JG. Analgesic efficacy of ultrasound-guided transversus abdominis plane block in patients undergoing open appendicectomy. Br J Anaesth 2007;104:193-7.
13. Shaaban AR. Ultrasound guided transversus abdominis plane block versus local wound infiltration in children undergoing appendectomy:A randomized controlled trial. Egypt J Anaesth 2014;30:377-82. [CrossRef]

14. Tupper-Carey DA, Fathil SM, Tan YK, Kan YM, Cheong CY, Siddiqui FJ, et al. A randomised controlled trial investigating the analgesic efficacy of transversus abdominis plane block for adult laparoscopic appendicectomy. Singapore Med J 2017;58:481-7. 